\title{
Development of the Rope-Climbing Ergometer for Physical Training and Testing
}

\section{(ㄷ) (2) (i) (5)}

Authors

Hiroshi Arakawa', Daisuke Kumagawa², Iwao Fujisaki ${ }^{3}$, Yoshiaki Ozawa³ ${ }^{3}$ Yusuke Ishige ${ }^{4}$

Affiliations

1 Physical Education, International Budo University, Katsuura, Chiba, Japan

2 Department of Physical Education, Kokushikan University, Tama, Tokyo, Japan

3 Research and Development, Apowatec Corporation, Yashio, Saitama, Japan

4 Department of Sports Sciences, Japan Institute of Sports Sciences, Kita, Tokyo, Japan

Key words

cycle ergometer, power, measurement, physiology, sport, athlete

received 22.03 .2017

revised $\quad 12.05 .2017$

accepted 16.05.2017

\section{Bibliography}

DOI https://doi.org/10.1055/s-0043-112335

Sports Medicine International Open 2017; 1: E128-E134

(c) Georg Thieme Verlag KG Stuttgart · New York

ISSN 2367-1890

\section{Correspondence}

Dr. Hiroshi Arakawa

International Budo University

Physical Education
841

2995295, Katsuura, Chiba, Japan

Tel.: + 81/470/734 111, Fax: + 814/707/34 111

arakawa@budo-u.ac.jp

\section{ABSTRACT}

The purpose of this study was to develop and characterize a rope-climbing ergometer. A custom-made loading device that has an eddy current brake with an electrical current control circuit was developed to impose resistive load on the rope. A calibration test was first performed using a three-phase induction motor to associate the scale of the load-level setting (100 levels) with the resultant traction force. The calibration test yielded criteria values of loads ( $123 \mathrm{~N}$ at Level 0 and $1064 \mathrm{~N}$ at Level 100). The human test was carried out by 14 male subjects. The participants performed eight sets of 10 -second maximaleffort exercises at different levels. Presumable trajectories of force, velocity, and power were obtained. The mean force increased by $161 \%$ (from $147.5 \mathrm{~N}$ at Level 0 to $383.7 \mathrm{~N}$ at Level 18 ), whereas the mean velocity decreased by $64.7 \%$ (from $1.87 \mathrm{~m} / \mathrm{s}$ at Level 0 to $0.66 \mathrm{~m} / \mathrm{s}$ at Level 18). The mean power reached its peak at Level $9(320 \mathrm{~W})$. The new rope ergometer for physical training and testing was successfully developed and characterized in this study. However, it remains to be seen whether its concurrent validity and reliability are qualifiable.

\section{Introduction}

Training, measurement, and evaluation of physical fitness, including strength, power, endurance, and flexibility are fundamental for athletes seeking to improve their performance. To assess aerobic and anaerobic capabilities, many practitioners and researchers have used cycle ergometry $[2,11,16,29]$. Ergometer measurements are typically performed in a laboratory instead of in field tests, allowing for precise quantification of the mechanical output with discretional choice of measuring protocols. Owing to these advantages, many studies have used ergometers to evaluate physiological characteristics and indices, such as the force-velocity relationship of muscle $[12,28]$, maximum anaerobic power $[4,10,30]$, anaerobic capacity [17], and maximum oxygen con- sumption [3]. Treadmills are also preferred by many technicians and researchers, because running recruits a larger active muscle mass with greater maximum oxygen consumption [3]. Nonetheless, the treadmill running tests need specialized biomechanical analyses to accurately quantify the mechanical work done by subject's lower limbs [18]. In this respect, ergometer tests allow for direct measurements of the load and offer significant advantages for calculating the true work in a way that the treadmill cannot [11]. For decades, many athletes and researchers have benefited from ergometry to evaluate physical fitness in athletes.

The ergometer methodology can be subdivided into various modes. The traditional cycle ergometer is most commonly used. It recruits a relatively large amount of muscle around the lower limbs and can elicit a large magnitude of power output $[11,30]$. 


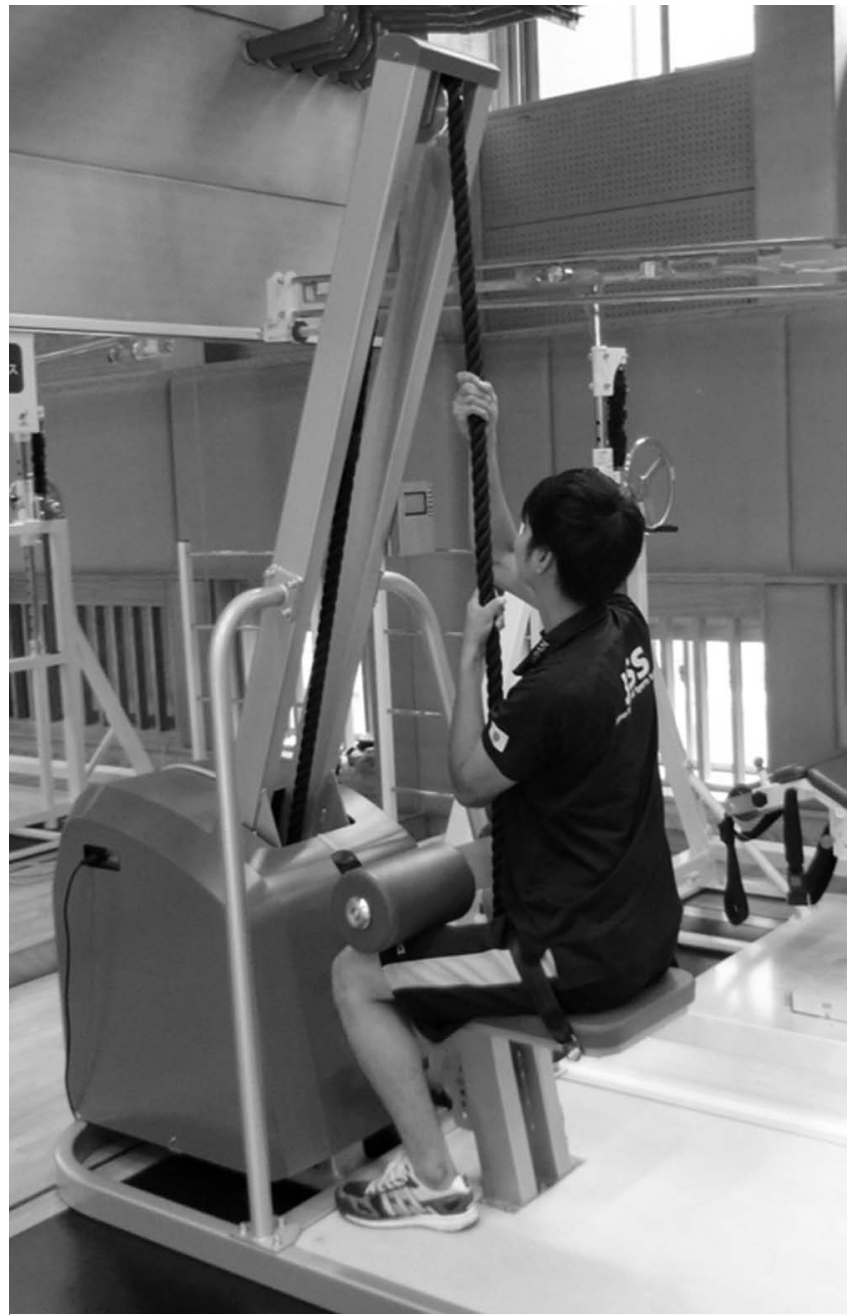

Fig. 1 Snapshot of the rope ergometer with a subject.

Validity and reproducibility of cycle ergometers have also been confirmed in previous studies [4, 6, 23, 24, 29]. Other methods have also been developed to duplicate specific conditions of each sport and approximate muscles that are involved [8, 22, 25-27], including an arm-cranking ergometer [7] and a rowing ergometer $[5,13,17,19,30]$. The ergometer test for physical fitness includes a variety of movements. To our knowledge, no gold standard has been established for upper limb exercise similar to the cycle ergometer for lower limbs. Further ingenious developments of laboratory ergometer methodologies for the upper body will increase options for physical measurement and evaluation of near-competitive conditions for a specific sport.

In this study, we developed a rope-climbing ergometer (rope ergometer) to assess and train subjects to pull using their upper limbs. Although a commercially available rope-climbing device already exists (VLT Rope Trainer, Marpo Kinetics, Livermore, CA, USA), it does not have a computerized measuring system equivalent to the ergometer. The movement pattern when an athlete is exercising with this device is similar to the cyclic (repetitive) action of running and cycling, suggesting its potential as an ergometer for tests of explosive, high-intensity, and endurance-intensity efforts. The

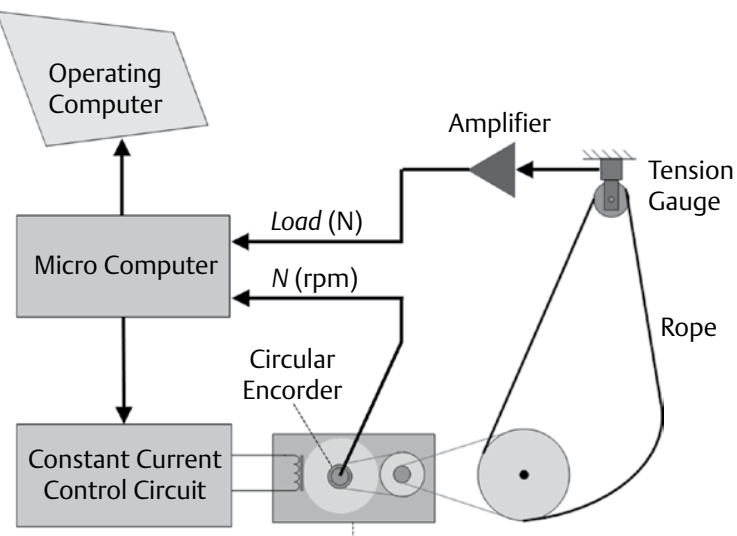

Eddy-Current Brake

- Fig. 2 Schematic overview of the custom-made loading system (Apowatec, Apowatec Corporation). This loading system involves an eddy current brake (ECB), which is regulated by an electrical current control circuit (ECCC). The intensity of the impressed current is controlled by a microcomputer ( $\mathrm{H}-8$, Renesas Electronics) and an operating computer. To configure the detailed programs for measurements and to display the summary of results, custom-made application software was developed and installed on the operating computer.

purpose of this study was to develop and characterize a rope-climbing ergometer that ensures the logical validity of measurements.

\section{Methods}

\section{The rope-climbing ergometer}

The overview and specifications of the rope ergometer developed in this study are represented in $>$ Fig. 1,2 and $\triangleright$ Table $\mathbf{1}$, respectively. Our ergometer resembles the commercially available ropetraining device (VLT Rope Trainer, Marpo Kinetics, Livermore, CA, USA) in terms of appearance and subject's motion. The difference is that the device has a comprehensive system for measurement that is characteristic of ergometers.

A custom-made loading system (Apowatec, Apowatec Corporation, Yashio, Japan; $>$ Fig. 2) was developed to a attain rigorously controlled resistive load on the rope. This loading system involves an eddy current brake (ECB), which is regulated by an electrical current control circuit (ECCC). In this system, the resistive torque can be generated in parallel with the magnitude of the impressed current in the ECCC. This torque is augmented by gears (gear ratio, 0.352 ) and transmitted to the pulley as resistive tension via the rope. The intensity of the impressed current is controlled by a microcomputer (H-8, Renesas Electronics, Tokyo, Japan) and an operating computer ( $\vee$ Fig. 2 ). To configure the detailed programs for measurements and to display the summary of results, custommade application software was developed and installed on the operating computer. Any operation and data output were handled with this application. 
The load-level settings consisted of 100 stages, and the axis was converted from an inverse logarithmic scale of the impressed current in the circuit, as follows:

Current $\cdot \mathrm{C}=\log$ Level

(Level=exp(Current.C))

Current represents the impressed current in the ECCC, Level represents the stage of the load-level setting, and $C$ is a constant representing the relationship between Current and Level. Both the number of stages (100) and C (0.141) can be discretionarily configured by users by modifying the application software on the computer. The relationships between the traction force loaded on the rope and both Current and Level are described below.

The instant traction force and velocity of the rope were measured using a tension gauge (LC-1205-K500, A and D) and circular encoder (E6A2-CW3C 360P/R 0.5M, OMRON). The tension gauge is located on the overhead pulley and directly detects the sum tension on the rope. Half of the tension measured by the gauge was defined as the instant traction force $\left(\mathrm{F}_{\text {ins }}\right)[\mathrm{N}]$ :

$F_{\text {ins }}=F_{\text {gauge }} / 2$

where $\mathrm{F}_{\text {gauge }}[\mathrm{N}]$ represents the instant tensile force directly measured by the tension gauge. The instant velocity $\left(\mathrm{V}_{\mathrm{ins}}\right)[\mathrm{m} / \mathrm{s}]$ was then calculated based on each elapsed time $\left(T_{\text {elapsed }}\right)[s]$, which is recorded by the circular encoder:

$\mathrm{V}_{\text {ins }}=\frac{\mathrm{D}}{\mathrm{T}_{\text {elapsed }}}$

$\mathrm{D}=0.547[\mathrm{~m}]$

where $\mathrm{D}$ is the distance between the landmarks that the rotary encoder detects. The data taken by the tension gauge and the circular encoder were transmitted to the microcomputer (sampling frequency is $100 \mathrm{~Hz}$ ) and then read into the operating computer with the application. The application has a simultaneous display function that represents the mechanical variables regarding the exercising information ( $>$ Fig. 2 ). The data were exported from the computer in a .csv format and forwarded for further analysis.

\section{Calibration test with a three-phase induction motor}

Before the tests, we performed a calibration test to associate the scale of both Level and Current with the resultant traction force loaded on the rope. In the calibration test, a three-phase induction motor (maximum output power: $1.5 \mathrm{~kW}$, G3LM-32-15-150, NISSEI) was used to pull the rope at constant speeds. The motor, which is virtually equivalent to a real human user, was fixed where the rope was on a pulley attached to the motor. Four sets of tests were examined at different pulling velocities $(0.25 \mathrm{~m} / \mathrm{s}, 0.50 \mathrm{~m} / \mathrm{s}, 0.75 \mathrm{~m} / \mathrm{s}$, and $1.00 \mathrm{~m} / \mathrm{s})$. It should be noted that the instant traction force fluctuates unintentionally from the acceleration of the rope even at the same load levels. In other words, the traction force stays fixed only when the rope is pulled at a constant speed, which is why this calibration test was conducted at the constant velocities using the induction motor.
- Table 1 Schematic specifications of the rope ergometer developed in this study.

\begin{tabular}{|c|c|}
\hline Items & Specifications \\
\hline \multirow[t]{2}{*}{ Size } & $\begin{array}{l}\text { Length: } 2000 \mathrm{~mm} \text {, width: } 1000 \mathrm{~mm} \text {, height: } \\
2300 \mathrm{~mm}\end{array}$ \\
\hline & Mass: Roughly $100 \mathrm{~kg}$ \\
\hline \multirow{4}{*}{ Structure } & Main body: Rectangular steel tube (STKR400) \\
\hline & Flooring: Slip-resistant rubber \\
\hline & $\begin{array}{l}\text { Cushions: PVC leather with cushioning } \\
\text { materials on ply board }\end{array}$ \\
\hline & $\begin{array}{l}\text { Rope: Polyester synthetic fiber ('Tetoron', } \\
\text { Toray), 甲 } 30 \mathrm{~mm}\end{array}$ \\
\hline \multirow{3}{*}{ Loading System } & Braking device: Eddy current brake \\
\hline & Control unit: Constant current control circuit \\
\hline & $\begin{array}{l}\text { Regulation: Pulse-width modulation by a } \\
\text { microcomputer (H-8 Renesas Electronics) and } \\
\text { an inverter }\end{array}$ \\
\hline \multirow[b]{2}{*}{ Measuring System } & Tension: Tension gauge (LC-1205-K500, A \& D) \\
\hline & $\begin{array}{l}\text { Velocity: Circular encoder (E6A2-CW3C } \\
\text { 360P/R 0.5M, OMRON) }\end{array}$ \\
\hline \multirow{4}{*}{$\begin{array}{l}\text { Settings of Exercise } \\
\text { Protocols }\end{array}$} & Load level: 100 stages (optional) \\
\hline & Duration of each set: Optional \\
\hline & Interval duration between each set: Optional \\
\hline & Number of sets: Optional \\
\hline \multirow{6}{*}{$\begin{array}{l}\text { Display Items on PC } \\
\text { Application }\end{array}$} & $\begin{array}{l}\text { Lapsed time (up to } 999 \text { min and } 59.9 \text { s with } \\
0.1 \text { s of resolution) }\end{array}$ \\
\hline & $\begin{array}{l}\text { Instant distance (up to } 999.9 \mathrm{~m} \text { with } 0.1 \mathrm{~m} \text { of } \\
\text { resolution) }\end{array}$ \\
\hline & $\begin{array}{l}\text { Instant traction Force (up to } 200.0 \mathrm{kgf} \text { with } \\
0.1 \mathrm{kgf} \text { of resolution) }\end{array}$ \\
\hline & $\begin{array}{l}\text { Instant traction velocity (up to } 4.00 \mathrm{~m} / \mathrm{s} \text { with } \\
0.01 \mathrm{~m} / \mathrm{s} \text { of resolution) }\end{array}$ \\
\hline & $\begin{array}{l}\text { Instant power (up to } 9999 \mathrm{~W} \text { with } 1 \mathrm{~W} \text { of } \\
\text { resolution) }\end{array}$ \\
\hline & $\begin{array}{l}\text { Instant work (up to } 9999 \text { J with } 1 \text { J of } \\
\text { resolution) }\end{array}$ \\
\hline Output of Data & As a csv file in the operating computer \\
\hline \multicolumn{2}{|c|}{$\begin{array}{l}\text { * The rope material may warrant reconsideration. In this study, } \\
\text { polyester was used because of its cost and durability advantages. On } \\
\text { the other hand, the features of hemp or polyamide are expected to } \\
\text { allow climbing without the hands sliding, which is not the case for } \\
\text { polyester. This issue is to be reconsidered in later studies. }\end{array}$} \\
\hline
\end{tabular}

- Fig. 3a describes the relationship between the Current and the resultant resistive forces at given pulling velocities. As depicted, the resistive forces at the identical Current tended to gradually become larger nonlinearly with increasing velocity. Importantly, the increments in the resistive forces progressively diminished with the gradual increase in velocity. When comparing the resistive forces at the identical Current, they approximately reached a ceiling above the velocity of $0.50 \mathrm{~m} / \mathrm{s}$. Therefore, it can safely be said that the resistive force at a given Current reached equilibrium at approximately $0.75 \mathrm{~m} / \mathrm{s}$. The force-Current relation (when the velocity $=0.75 \mathrm{~m} / \mathrm{s}$ ) was fitted to a quadratic function. As shown, the relationship was well described $\left(r^{2}=1.00\right)$ with the quadratic equation below: 

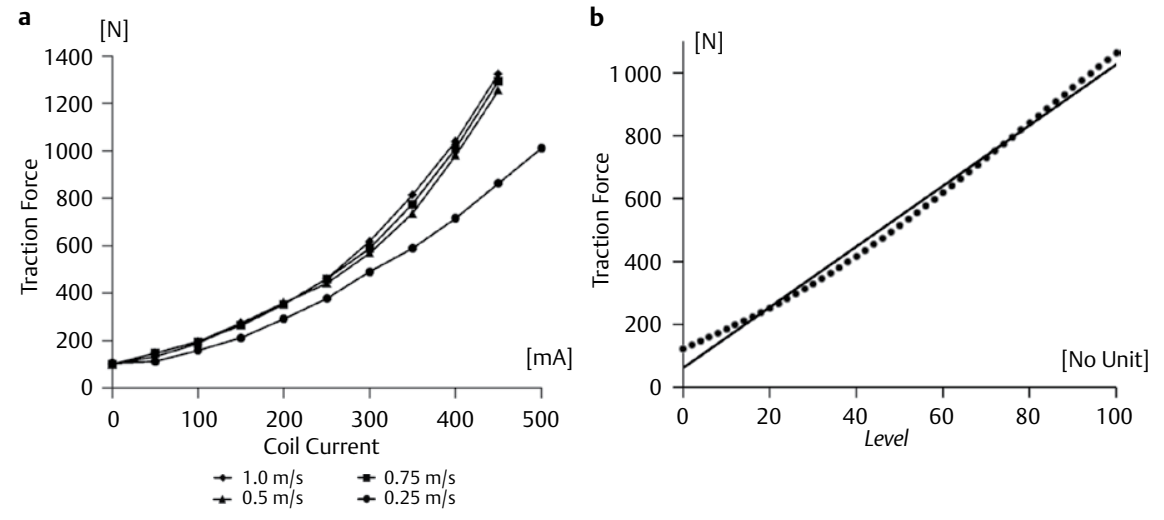

Fig. 3 The results of the calibration test with a three-phase induction motor. a The relationship between the Current and the resultant resistive forces at given pulling velocities. As depicted, the resistive forces at the identical Current tended to gradually become larger nonlinearly with increasing velocity. $\mathbf{b}$ The relationship between the Level and the resultant resistive forces when the velocity $=0.75 \mathrm{~m} / \mathrm{s}$. In this figure, the axis of Level was converted from an inverted logarithmic scale of Current.

$\mathrm{F}_{0.75}=\mathrm{a}_{1} *$ Current $^{2}+\mathrm{a}_{2} *$ Current $+\mathrm{a}_{3}$

where $F_{0.75}$ is the resistive force when the pulling velocity was set at $0.75 \mathrm{~m} / \mathrm{s}$, and $\mathrm{a}_{1}, \mathrm{a}_{2}, \mathrm{a}_{3}$ represent constants, respectively $\left(a_{1}=0.0059, a_{2}=-0.1392, a_{3}=129.81\right)$.

- Fig. 3 b represents the plots of the $F_{0.75}$ as a function of the Level; $123 \mathrm{~N}$ of resistive force was observed when the Level was set at the minimum (i. e., Level $=0$ ). With the increment of the Level, $\mathrm{F}_{0.75}$ increased approximately linearly. The force-Level relation (velocity $=0.75 \mathrm{~m} / \mathrm{s}$ ) was fitted to a linear function with a moderately fitted regression line $\left(r^{2}=0.99\right)$ as shown below:

$\mathrm{F}_{0.75}=\mathrm{b}_{1} *$ Level $+\mathrm{b}_{2}$

where $b_{1}$ and $b_{2}$ represent constants, respectively $\left(b_{1}=9.8603\right.$, $\left.b_{2}=61.257\right)$. It should be also noted that each constant $\left(a_{1}, a_{2}, a_{3}\right.$, $b_{1}$, and $b_{2}$ ) can be forced to change when $C$ is discretionally modified by adjusting the software.

\section{The tests by subjects}

Fourteen healthy, injury-free males participated in the experiment. All participants were active individuals but not ongoing competitive athletes. Their mean ( \pm SD) age, height, and body mass were $32.6 \pm 6.0$ years, $1.738 \pm 0.049 \mathrm{~m}$, and $74.9 \pm 12.7 \mathrm{~kg}$, respectively. All participants refrained from intense activities on the previous day to prevent unintentional fatigue during the tests. Informed consent was obtained from all participants after explaining the purpose and design of the study. This experiment was approved by the Ethics Committee of the Japan Institute of Sports Sciences and meets the ethical standards of the journal [15].

The participants performed eight sets of maximal-effort ropeclimbing trials. Based on previously reported load-power relationships $[1,10,20]$, we varied the Levels $(0,3,6,9,12,15,18$, and 21 , respectively). The exercise duration was configured for $10 \mathrm{~s}$ at Level $\leq 9$, and 7 s at Level $>12$, to avoid an excess fatigue. Eight sets of trials were performed in a random order to offset the order ef- fect, with at least a 10-minute rest period between each successive trial.

Each participant performed light aerobic exercises with the rope ergometer and stretches of muscles relevant to the pulling exercise to warm up before the tests. The trials were carried out in a sitting posture on the seat of the ergometer. The participant's thighs were tightly secured against a pad to keep their body stationary during exercise. The subjects raised their hands above the head and firmly gripped the rope before the beginning of the tests. It was optional how the subjects configured their posture in particular. All operations concerning the machinery and verbal cues including countdown were given by the assessors.

We analyzed the data exported to the computer. The time of the force and velocity were smoothed with a nine-sample simple moving average process, and then the instant power was calculated. In the pilot experiment, the time-course data of force and power contained cyclically spiked waveforms, probably because of the changeovers of the right and left hands (e. g., > Fig. 4), which the moving average process failed to remove. Consequently, data from each time course were used to evaluate a peak value [4] and averaged for three seconds (from two seconds after the initial moment) for each trial. This time period was based on the qualitative observations of the data from each time course throughout the Levels in the pilot experiment.

Comparisons of force, velocity, and power between the Levels were performed through one-way repeated-measures ANOVAs with Bonferroni-adjusted pairwise post-hoc analyses. The significance level was set at $P<0.05$. All statistical analyses were performed using R Statistical Software (version 3.3.3; R Foundation for Statistical Computing, Vienna, Austria).

\section{Results}

Typical examples of time series trajectories of the force, the velocity, and the power are shown in - Fig. 4. These data are chosen from a single subject. We observed cyclically spiked waveforms of 
a

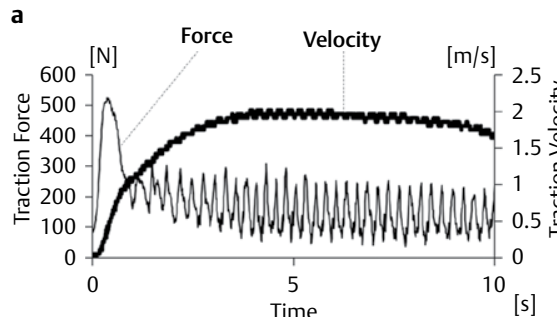

C

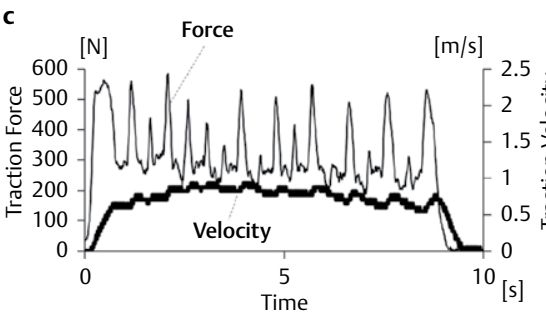

b

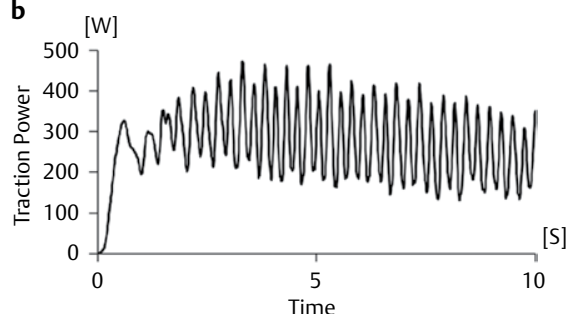

d

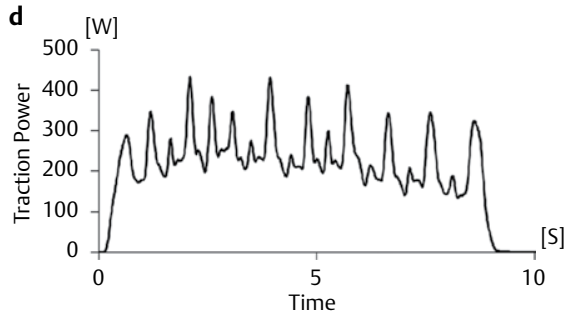

- Fig. 4 Typical examples of time series trajectories of force, velocity (a and $\mathbf{c}$ ), and power (b and $\mathbf{d}$ ), when Level was set relatively low (Level 3, a and b) and high (Level 15, $\mathbf{c}$ and $\mathbf{d}$ ), respectively. These data are chosen from a single subject.
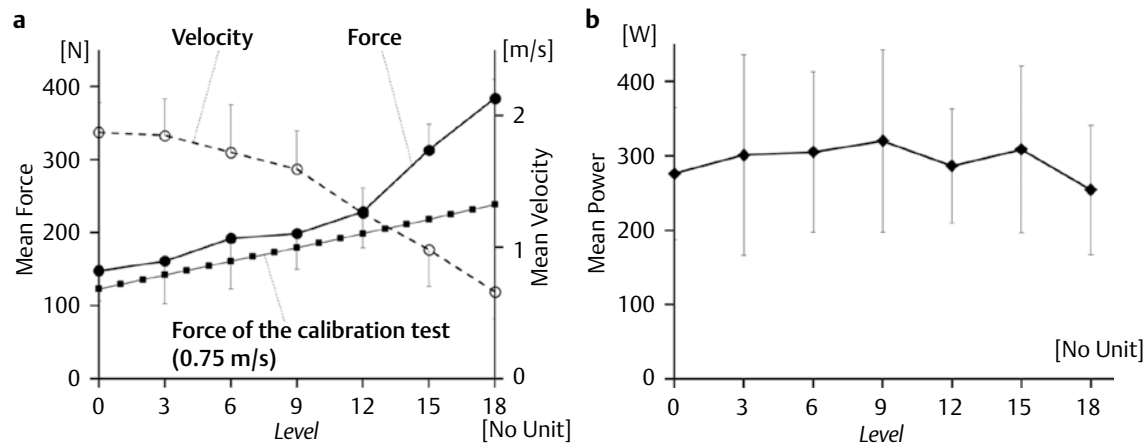

Fig. 5 Averaged forces (a), velocities (a), and powers (b) as functions of Level for 14 subjects. These plots are the mean values between two and five seconds after onset of exercises. In a, the results of force in the calibration test $(0.75 \mathrm{~m} / \mathrm{s})$ were also plotted for comparison between the calibration and the human tests.

force and power for every trial and subject ( $\triangleright$ Fig. 4), presumably due to transitions between the right and left hands. The frequency of these spikes was relatively higher in the trials with low load levels ( $\triangleright$ Fig. 4a,b), and decreased with increasing load levels ( $\vee$ Fig. 4c,d). The length of time spent to achieve peak velocity ranged from two to four seconds after onset regardless of the Level ( $\vee$ Fig. 4a,c). The peak values for the trajectory of force were found immediately after onsets ( $\triangleright \mathbf{F i g .} \mathbf{4 a}, \mathbf{c}$ ), and its relative size compared with the subsequent force tended to be larger when the Level was low ( $\triangleright$ Fig. 4a). We were unable to discern the exact time required for the peak force and power because of the influence of the spike noises.

The time series for the force, velocity, and power were averaged between two and five seconds after onsets for all the load levels, and plotted on $\mathbf{F i g}$. 5a,b. The one-way ANOVA indicated that there were significant differences between the Levels in all of these three variables $(p<0.01$ in force and velocity and $p<0.05$ in power). Regarding the comparisons between adjacent Levels, the post-hoc analyses indicated that significant differences were observed between Level 12 vs. 15 ( $p<0.01)$ and 15 vs. $18(p<0.01)$ in force, between 9 vs. 12 $(p<0.01), 12$ vs. $15(p<0.01)$, and 15 vs. $18(p<0.01)$ in velocity, and 15 vs. $18(p<0.01)$ in power ( $>$ Fig. 5 a,b). As a function of Level, the mean force increased by $161 \%$ on average (from $148 \pm 41 \mathrm{~N}$ at Level 0 , to $384 \pm 26 \mathrm{~N}$ at Level 18 ), whereas the mean velocity decreased by $64.7 \%$ (from $1.87 \pm 0.23 \mathrm{~m} / \mathrm{s}$ at Level 0 , to $0.66 \pm 0.20 \mathrm{~m} / \mathrm{s}$ at Level 18). Magnitudes of the increments of force and the decrements of velocity with increasing Level tended to be smaller at lower Levels, and became larger at higher Levels ( $\triangleright$ Fig. 5a). The mean power reached its peak at Level $9(320 \pm 123 \mathrm{~W}$ : Level 9$)$, although the post-hoc comparison indicated that there were no significant differences of powers between adjacent Levels ( $p>0.05$ between Level 8 vs. Level 9 and between Level 9 vs. Level 10). 


\section{Discussion}

In this study, we developed the new rope climbing ergometer and provided a mechanical characterization of its device. To our knowledge, our rope ergometer is the first that combines the rope-climbing exercise with the function of an ergometer. This device has a potential for use in physical training and evaluation of the upper limbs, particularly focusing on muscles relevant to the pulling movement.

The most elaborate component of our ergometer is the loading system (Apowatec, Apowatec Corporation, Yashio, Japan). Existing ergometers include various loading devices [6], such as the ECB (PowerMax V3 Series, Combi Wellness Corporation, Tokyo, Japan), and friction-based loading (Monark Series, Monark Exercise AB, Vansbro, Sweden). In our study, the ECB was adopted because it has an advantage in strictness and easiness of load adjustment. The rope ergometer has provided for the arbitrary control of the Level by handling the computer, offering a user-friendly equivalent to the existing commercial ergometers such as the PowerMax V3 series. This indicates that the present ergometer is suitable to assess peak power, considering the load-power (as well as the force-velocity) relations of muscle $[1,9,28]$. In addition, our device allows for the detailed organization of measuring protocols including Levels, durations, sets, intervals, and combinations. These functional capabilities suggest the potential applicability of the present rope ergometer to both practical situations of training and testing and to laboratory tests.

The present rope ergometer quantifies the mechanical outputs (i. e., force and velocity) based on the actual observations using the tension gauge (located on the overhead pulley) and the circular encoder (placed inside the main unit), respectively ( $\bullet$ Fig. 2 ). It is reasonable to suppose that there is no room for substantial error in these mechanical variables, because no interfering factors exist in these measurements and calculations. With regard to the other factors that might cause possible error, the hardware side of the rope ergometer should be taken into consideration. In particular, mechanical friction originating from the rope, pulleys, and gears is assumed to influence the results of the traction force measurement. Yet the estimated values of force and velocity are assumed to be acceptably accurate, because in the present ergometer the tension gauge and the circular encoder directly evaluate the measured values exerted by a subject, and hence the measuring processes are independent of the ergometer hardware. Nevertheless, it should be noted that this study lacks the examination of concurrent validity and reliability. Therefore in the future, it remains to be seen whether the ergometer's validity, reliability, and sensitivity are qualifiable as a tool for measuring the power of the upper limbs [24].

In this study, the calibration test was conducted with a threephase induction motor to associate the scales of Level and Current with the resultant traction force. In this regard, we should mention that there was a considerable difference in the observed traction forces between the subject test and the calibration test ( $\vee$ Fig. 5a), even when the Level was identical. In particular, the traction forces observed in the subject test resulted in larger values than those observed in the calibration test when the Level was set relatively higher (e. g., the former was $313 \pm 36 \mathrm{~N}$ vs. the latter was $218 \mathrm{~N}$ at Level 15 , and $384 \pm 26 \mathrm{~N}$ vs. $238 \mathrm{~N}$ at Level 18 ). Supposedly, the magni- tudes of the traction force observed in the two tests ought to unambiguously correspond to each other regardless of the Level setting, provided the velocity of the rope is constant (the filled plots in $>$ Fig. $\mathbf{5 a}$ were supposed to overlap $>$ Fig. $\mathbf{3 b}$ ). The factor that caused the gap between the two tests (i. e., the subject test and the calibration test) would be the effect of acceleration of the rope, because the acceleration instantly boosts the Current and thus the load on subjects. In the case of the subject test, inevitable acceleration and deceleration of the rope occur during use, largely because of the cyclic replacement of right and left hands. These fluctuations in the velocity of the rope would result in the increase in traction force in the case of the subject test, whereas the rope velocity was mechanically kept constant in the calibration test, which used the motor. In addition, it should also be noted that the gap in the traction forces became greater with the increment in the load levels. This is probably because the load level was so intense at Levels 15 and 18 that the subjects changed the manner of pulling, such as suspending their upper body from the rope, thus resulting in the conspicuous fluctuation in velocity. In light of these results, when using this ergometer at higher Level settings, it should be noted that actual traction force applied to the subject becomes larger nonlinearly.

In the subject test, the peak power resulted in $320 \pm 123 \mathrm{~W}$ (Level $=9$, > Fig. $\mathbf{5 b}$ ) on average. This magnitude is smaller than those of the preceding studies that used the cycle [20] and the rowing [17] ergometers. Regarding cycle ergometry, an interpolating calculation with regression formulae has been generally used to estimate the peak power over various loads. With the use of this calculation, the peak power with the cycle ergometer was recorded around $930 \mathrm{~W}$ for adult male non-athletic subjects [20] and up to $1600 \mathrm{~W}$ for male elite cyclists [10]. As for the rowing ergometer, Klasnja et al. (2010) reported that $522 \mathrm{~W}$ of peak power was observed for male rowers [17]. A presumable rationale for the smaller peak power with the present ergometer is the total volume of muscles involved in the pulling exercise. Namely, with the rope ergometer, muscles of the upper limbs and some trunk muscles are assumed to be mainly recruited, whereas muscles of the lower limbs, which are comparatively large in volume, are involved in exercises with the cycle and the rowing ergometers. Nonetheless we ought not to get into further discussion on this issue, because none of the biomechanical and electromyographic measurements were included in this study. These measurements remain to be investigated in future studies.

Meanwhile, the present results should also be compared with those of the arm cranking ergometer, which like the present rope ergometer, mainly engages muscles of upper limbs and some part of trunk. Indeed, Flueck et al. (2015) applied an arm cranking ergometer to non-athletic individuals in a sitting posture, and observed that the peak power was from $312 \mathrm{~W}$ to $334 \mathrm{~W}$ [14], indicating a value close to that of the present study. On the other hand, Neville et al. (2010) observed the peak power (up to $1347 \mathrm{~W}$ ) to be four times greater than in the present study [21]. It should be noted that there are two fundamental differences between Neville et al. (2010) and the present study; in the preceding study, the participants were professional yacht racers and the tests were carried out with participants in a standing position [21]. Concerning the rope ergometer, it is highly likely that the magnitudes of peak power 
would change with variations in the testing conditions (e.g., profiles of subjects and testing posture). This issue will become apparent with practical use.

\section{Conclusions}

We developed and characterized the new rope-climbing ergometer in this study. This new device has a potential for use in the physical training and testing of upper limbs. However, future study is warranted to verify whether its concurrent validity, reliability, and sensitivity are qualifiable as a tool for measuring power.

\section{Conflict of Interest}

The authors declare that they have no conflict of interest.

\section{References}

[1] Baker JS, Thomas NE, Davies B. Physiological, biochemical and mechanical issues relating to resistive force selection during high-intensity cycle ergometer exercise. J Exerc Sci Fit 2009; 7: S51-S60

[2] Bar-Or O. The Wingate Anaerobic Test. An update on methodology, reliability and validity. Sport Med 1987; 4: 381-394

[3] Basset FA, Boulay MR. Specificity of treadmill and cycle ergometer tests in triathletes, runners and cyclists. Eur J Appl Physiol 2000; 81: 214-221

[4] Bell W, Cobner DM. Effect of individual time to peak power output on the expression of peak power output in the 30-s Wingate Anaerobic Test. Int J Sports Med 2007; 28: 135-139

[5] Benson A, Abendroth J, King D, Swensen T. Comparison of rowing on a concept 2 stationary and dynamic ergometer. J Sport Sci Med 2011; 10: $267-273$

[6] Bertucci WM, Grappe F, Crequy S. Original characteristics of a new cycle ergometer. Sport Eng 2011; 13: 171-179

[7] Bulthuis Y, Drossaers-Bakker W, Oosterveld F, van der Palen J, van de Laar M. Arm crank ergometer is reliable and valid for measuring aerobic capacity during submaximal exercise. J Strength Cond Res 2010; 24: 2809-2815

[8] Callewaert M, Geerts S, Lataire E, Boone J, Vantorre M, Bourgois ]. Development of an upwind sailing ergometer. Int J Sports Physiol Perform 2013; 8: 663-670

[9] Dorel S, Couturier A, Lacour JR, Vandewalle H, Hautier C, Hug F. Force-velocity relationship in cycling revisited: Benefit of two-dimensional pedal forces analysis. Med Sci Sports Exerc 2010; 42: 11741183

[10] Dotan R, Bar-Or O. Load optimization for the Wingate Anaerobic Test. Eur J Appl Physiol Occup Physiol 1983; 51: 409-417

[11] Driss T, Vandewalle $H$. The measurement of maximal (anaerobic) power output on a cycle ergometer: A critical review. Biomed Res Int 2013; 2013: 589361
[12] Driss T, Vandewalle H, Le Chevalier JM, Monod H. Force-velocity relationship on a cycle ergometer and knee-extensor strength indices. Can J Appl Physiol 2002; 27: 250-262

[13] Elliott B, Lyttle A, Birkett O. The rowperfect ergometer. Sport Biomech 2001; 1: 1-15

[14] Flueck JL, Lienert M, Schaufelberger F, Perret C. Reliability of a 3-min all-out arm crank ergometer exercise test. Int J Sports Med 2015; 36: 809-813

[15] Harriss D], Atkinson G. Ethical standards in sports and exercise science research: 2016 update. Int J Sports Med 2015; 36: 1121-1124

[16] Inbar O, Bar-Or O, Skinner JS. The Wingate Anaerobic Test. Illinois: Human Kinetics; 1996: 120

[17] Klasnja A, Barak O, Popadić-Gaćesa J, Drapsin M, Knezević A, Grujić N. Analysis of anaerobic capacity in rowers using Wingate test on cycle and rowing ergometer. Med Pregl 2010; 63: 620-623

[18] Luhtanen P, Rahkila P, Rusko H, Viiasalo J. Mechanical work and efficiency in treadmill running at aerobic and anaerobic thresholds. Acta Physiol Scand 1990; 139: 153-159

[19] Mikulic P, Smoljanovic T, Bojanic I, Hannafin J, Pedisic Z. Does 2000-m rowing ergometer performance time correlate with final rankings at the World Junior Rowing Championship? A case study of 398 elite junior rowers. J Sports Sci 2009; 27: 361-366

[20] Nakamura Y, Mutoh Y, Miyashita M. Determination of the peak power output during maximal brief pedalling bouts. J Sports Sci 1985; 3: 181-187

[21] Neville V, Pain MTG, Kantor J, Folland JP. Influence of crank length and crank-axle height on standing arm-crank (grinding) power. Med Sci Sports Exerc 2010; 42: 381-387

[22] Niesing R, Eijskoot F, Kranse R et al. Computer-controlled wheelchair ergometer. Med Biol Eng Comput 1990; 28: 329-338

[23] O'Kroy JA. Wingate power output testing on a recumbent ergometer. J Strength Cond Res 2000; 14: 405-410

[24] Paton CD, Hopkins WC. Ergometer error and biological variation in power output in a performance test with three cycle ergometers. Int ] Sports Med 2006; 27: 444-447

[25] Ridge BR, Pyke FS, Roberts AD. Responses to kayak ergometer performance after kayak and bicycle ergometer training. Med Sci Sports 1976; 8: 18-22

[26] Shionoya A, Shibukura T, Koizumi M et al. Development of ergometer attachment for power and maximum anaerobic power measurement in swimming. Appl Human Sci 1999; 18: 13-21

[27] Simmelink EK, Wempe JB, Geertzen JHB, Dekker R. Repeatability and validity of the combined arm-leg (Cruiser) ergometer. Int J Rehabil Res 2009; 32: 324-330

[28] Sprague RC IV, Martin JC, Davidson C], Farrar RP. Force-velocity and power-velocity relationships during maximal short-term rowing ergometry. Med Sci Sports Exerc 2007; 39: 358-364

[29] Vandewalle $\mathrm{H}$, Pérès G, Monod $\mathrm{H}$. Standard anaerobic exercise tests. Sports Med 1987; 4: 268-289

[30] Zupan MF, Arata AW, Dawson LH, Wile AL, Payn TL, Hannon ME. Wingate Anaerobic Test peak power and anaerobic capacity classifications for men and women intercollegiate athletes. J Strength Cond Res 2009; 23: 2598-2604 